\title{
UTILIZATION OF DIFFERENT MODIFIED ATMOSPHERE PACKAGING (MAP) ON POSTHARVEST PERISHABLE CROPS
}

\author{
ARNOLD V. DAMASO, MSC \\ Faculty Member of the College of Agriculture, Nueva Ecija University of Science and Technology - Gabaldon Campus, \\ Gabaldon, Nueva Ecija
}

\begin{abstract}
The packaging or storage of harvested produce in an atmosphere different from the normal air concerning the concentration of $\mathrm{N} 2, \mathrm{O} 2$, and $\mathrm{CO} 2$ is called atmosphere modification. This technique is attained with the use of permeable polymer films as packaging materials or atmosphere generator - equipped storage facilities. The modified atmosphere also is the practice of modifying the composition of the internal atmosphere of a package (commonly food packages, drugs, etc.) to improve the shelf life. The experiment was laid out following the Randomized Complete Block Design. There was equally divided into three (3) replications and four (4) treatments. The following treatments were used in this study: Treatment 1 - Control (Expose or place in an open container); Treatment 2 - no hole; Treatment 3 - 10 pinprick diffusion holes; Treatment 4 - 10 puncher size perforations. On the other, to complete the experiment the following materials were used in this study: Generally fruits and vegetable quality deteriorated during storage as weight loss decreased and increased. Firmness decreased during the storage, regardless of the vegetable, and was the most important limiting quality factor for most vegetables evaluated. Changes in color usually followed in tissue firmness. Vegetable developed a dark coloration and overripe (over storage) appearance, became green to $75 \%$ yellow, and less bright green. Shriveled, wilted dry appearance developed when only textural and color changes were already noticeable at the same time as weight loss attained a maximum threshold, which was dependent on the vegetable evaluated. However, a significant linear correlation was found between the other treatments and parameters like weight loss, several days the crops become unfit for consumption and degrees of wilting. Therefore, maximum postharvest life, when the vegetable became unacceptable for sale to impaired visual quality under the different storage used in this study. Deterioration of vegetable, visual quality may not be exclusively attributed to water loss, but rather to a summation of many appearance defects, some of which may result from excessive loss of water.
\end{abstract}

KEYWORDS: Postharvest, Perishable crops, Modified atmosphere packaging, Storage \& Respiration

Received: May 13, 2020; Accepted: Jun 03, 2020; Published: Aug 04, 2020; Paper Id.: IJMPERDJUN2020601

\section{INTRODUCTION}

The packaging or storage of harvested produce in an atmosphere different from the normal air concerning the concentration of $\mathrm{N}_{2}, \mathrm{O}_{2}$, and $\mathrm{CO}_{2}$ is called atmosphere modification. This technique is attained with the use of permeable polymer films as packaging materials or atmosphere generator - equipped storage facilities. Fruits and vegetables subjected to the modified atmosphere have extended storage life brought about by the decrease in respiration and transpiration rate.

It also adds significantly to the development and challenges of ensuring food security and reducing poverty. Increasing the population density of plant is an agronomical practice that has been studied. This crop technique has evolved and will continue to evolve over the years and it is agronomic management factor that has changed Damaso, 
(2020).

Modified atmosphere packaging (MAP) refers to the technique of sealing actively respiring produce in plastic film packages to modify $\mathrm{O}_{2}$ and $\mathrm{CO}_{2}$ levels within the package atmosphere. It improves moisture retention and reduces product exposure to contaminants. Other benefits of MAP include thee reduction of respiration, ethylene production and sensitivity to ethylene, prevention of softening and compositional changes, and alleviation of certain physiological disorders and reduced decay incidence.

The modified atmosphere also is the practice of modifying the composition of the internal atmosphere of a package (commonly food packages, drugs, etc.) to improve the shelf life. The modification process often tries to lower the amount of oxygen $\left(\mathrm{O}_{2}\right)$, moving it from $20.9 \%$ to $0 \%$, to slow down the growth of aerobic organisms and the speed of oxidation reactions. The removed oxygen can be replaced with nitrogen $\left(\mathrm{N}_{2}\right)$, commonly acknowledged as an inert gas, or carbon dioxide $\left(\mathrm{CO}_{2}\right)$, which can lower the $\mathrm{pH}$ or inhibit the growth of bacteria. Carbon monoxide can be used for preserving the red color of meat. Re-balancing of gases inside the packaging can be achieved using active techniques such as gas flushing and compensated vacuum or passively by designing "breathable" films known as equilibrium modified atmosphere packaging (EMAP). Packets containing scavengers may be used.

\section{METHODS AND MATERIALS}

The experiment was laid out following the Randomized Complete Block Design. There was equally divided into three (3) replications and four (4) treatments. The following treatments were used in this study: Treatment 1 - Control (Expose or place in an open container); Treatment 2 -no hole; Treatment $3-10$ pinprick diffusion holes; Treatment $4-10$ puncher size perforations. On the other, to complete the experiment the following materials were used in this study: Fresh vegetable (pechay, string beans, sweet potato leaves, calamansi), plastic tape, puncher ( $70 \mathrm{~mm}$ size), polyethylene plastic bags, ziplock. A fresh vegetable (pechay, string beans, sweet potato leaves, calamansi) were placed in polyethylene plastic bags (the size is enough to accommodate the samples) with a different number of holes which served as the treatment. The bags/ziplock was closed using plastic tape or properly tied with a rubber band. The weight of the sample per bag is 250 grams. The size of the hole is $70 \mathrm{~mm}$ (puncher size). The treatments were replicated three times. Store in ambient condition and Observe the experimental set - up for five (5) consecutive days or until the crop attained VQR 3.

\section{EXPERIMENTAL OBSERVATION}

To assess the effect of various treatments, different modified atmospheric packaging on perishable crops like percent weight loss of the crops (\%), color change of the crops, degrees of wilting and the number of days to the crop become unfit for consumption.

\section{Statistical Analysis of Data}

Data collected were organized, tabulated, and analyzed using Analysis of Variance (ANOVA) for Randomized Complete Block Design (RCBD). The IRRI STAR (version 2.0.1) was used to run the ANOVA. Means were compared using Tukey's Honest Significant Difference (HSD) Test at 0.05 level of confidence.

\section{RESULTS AND DISCUSSIONS}

The results obtained from the field experiments conducted to study the utilization of different modified atmosphere packaging 
(MAP) of perishable crops are briefly summarized hereunder. The treatments their effects were investigated on the importance of the impact in terms of postharvest commodities.

Percent weight loss. The utilization of different modified atmospheric packaging on perishable crops in terms of percent weight loss. It was noted that percent weight loss was significantly $(p \leq 0.05, H S D)$ affects the modified atmospheric packaging on perishable crops and it was registered in Treatment 2 (No hole) with a mean of 94.00\%. Substantial water loss may result in a significant loss of fresh weight, resulting in an economic loss of the commodity. However, Treatment 2 (no hole) become early unfit for consumption, it is because the variable or the experimental crops is fast wilting after 2-3 days of storing the crops, the condition in the ziplock is not appropriate to release the air inside the ziplock/container and this is why the pechay is easily wilted. Corroborates with the finding of Edmond (2007), that loss of water from the container (ziplock) especially in no hole has a great impact on vegetable quality and is a major cause of deterioration. Nevertheless, the quality of most vegetables declines very fast in terms of moisture loss, and in a general loss of 94.00 percent of the highest percentage weight loss may render a wide range of horticultural crops unacceptable for sale.

\section{Color Change}

The color is an important quality index and should be preserved until the vegetable is sold. However, these disorders affect internal and external quality, mainly the appearance of leafy vegetables. The appearance of leafy vegetables is important to be attractive for consumers and it is an important quality index and should be preserved until the vegetable is for consumption. Nevertheless, the color change in the first visible symptom of senescence that compromises their economic value. It was concluded that there is a significant $(p \leq 0.05$, HSD) impact on the modified atmospheric packaging. Treatment 2 registered the highest mean of changing in color with a mean of 16.00. This effect is due to the efficiently change the color that affects the physiology and senescence process that it has occurred. Based on the physiological changes appropriate and affects the postharvest life of the crops. However, the rate of biological deterioration the affects the change in color depends on various environmental (external) factors such as temperature, relative humidity atmospheric composition, pressure as stated by Cantwell et al., (2015).

\section{Degrees of Wilting}

The degrees of wilting significantly $(p \leq 0.05, H S D)$ affect the different modified atmospheric packaging. It was noted that water loss and wilting of leafy vegetables are mostly water $(>90 \%)$ and have the propensity to lose water through transpiration (evaporation of water from plant tissues). Water loss is the main cause of weight loss (loss in saleable weight) and wilting. A loss of 5-10\% of fresh weight would make leafy vegetables appear wilted and become unusable as cited by Kanlayanarat, 2007. Treatment 1 (Control (Expose or place in an open container) registered the fastest to decrease/water loss that incurred wilting. According to O'Hare et al., (2001), that in pechay, wilting is primarily due to water loss through the stomata that water loss also induces degradation of nutritional components (e.g. vitamin C loss) and imposes stress (i.e. water stress) that increases respiration and ethylene production. Water loss was measured at $2.8 \%$ per hour at $35^{\circ} \mathrm{C}$. Complete closure of all stomata occurs between 10-15\% moisture losses. Wilting occurred more rapidly in leaves with lower initial water potential. Water potential in pechay (leafy vegetables) was highest when harvested at 0400 and $2200 \mathrm{~h}$. However, wilting due to water loss, senescence-associated discoloration (yellowing or browning), mechanical injury, high respiration rate, and decay or rotting are the main causes of quality deterioration and postharvest loss of leafy vegetables. These causes of quality loss are physiological, pathological, and mechanical 
Number of days the crop becomes unfit for Consumption

The Treatment 2 shows a significant ( $p \leq 0.05$, HSD) findings that about 2-3 days the crops become (early) unfit for consumption because of the container or the ziplock may not deteriorate outside, the air circulate on the container/ziplock which is the main reason why the crops easily wilt and not for consumption. However, Treatment 3 , become (longer) unfit for consumption because it maintains the circulation of the air from the container/ziplock. Owing to that the substantial loss of the moisture of leafy vegetables that were used during the storing the crops. It was observed that optimal temperature and relative humidity during storage may help to reduce the degenerative process that occurs during the postharvest stages. Moreover, this effect understands the behavior of leafy vegetables during the hypothetical storage for 5 days.

Table 1: Utilization of Different Modified Atmospheric Packaging (MAP) on Perishable Crops on percent weight loss (\%), color change, degrees of wilting, and Number of days the crops become unfit for consumption.

\begin{tabular}{|l|c|c|c|c|}
\hline \multicolumn{1}{|c|}{ Treatments } & $\begin{array}{c}\text { Percent Weight } \\
\text { Loss }\end{array}$ & $\begin{array}{c}\text { Color } \\
\text { Change }\end{array}$ & $\begin{array}{c}\text { Degrees of } \\
\text { Wilting }\end{array}$ & $\begin{array}{c}\text { Number of days the crop } \\
\text { become unfit for } \\
\text { consumption }\end{array}$ \\
\hline $\begin{array}{l}\text { Treatment 1 - Control (Expose or place in } \\
\text { an open container) }\end{array}$ & $\mathbf{9 0 . 3 3}^{\mathbf{a}}$ & $\mathbf{1 5 . 3 3}^{\text {ab }}$ & $\mathbf{1 7 . 0 0}^{\mathbf{a}}$ & $\mathbf{3 . 3 3}^{\text {ab }}$ \\
\hline Treatment 2 - no hole & $\mathbf{9 4 . 0 0}^{\mathbf{a}}$ & $\mathbf{1 6 . 0 0}^{\mathbf{a}}$ & $\mathbf{1 6 . 3 3}^{\mathbf{a}}$ & $\mathbf{2 . 6 7}^{\mathbf{b}}$ \\
\hline Treatment 3 - 10 pinprick diffusion holes & $\mathbf{7 2 . 0 0}^{\mathbf{b}}$ & $\mathbf{1 5 . 0 0}^{\mathbf{b c}}$ & $\mathbf{1 5 . 0 0}^{\mathbf{b c}}$ & $\mathbf{4 . 3 3}^{\mathbf{a}}$ \\
\hline Treatment 4- 10 puncher size perforations & $\mathbf{7 9 . 3 3}^{\mathbf{b}}$ & $\mathbf{1 3 . 0 0}^{\mathbf{c}}$ & $\mathbf{1 4 . 0 0}^{\mathbf{c}}$ & $\mathbf{3 . 0 0}^{\mathbf{b}}$ \\
\hline
\end{tabular}

Means with the same letter are not significantly different $p \leq 0.05, H S D$

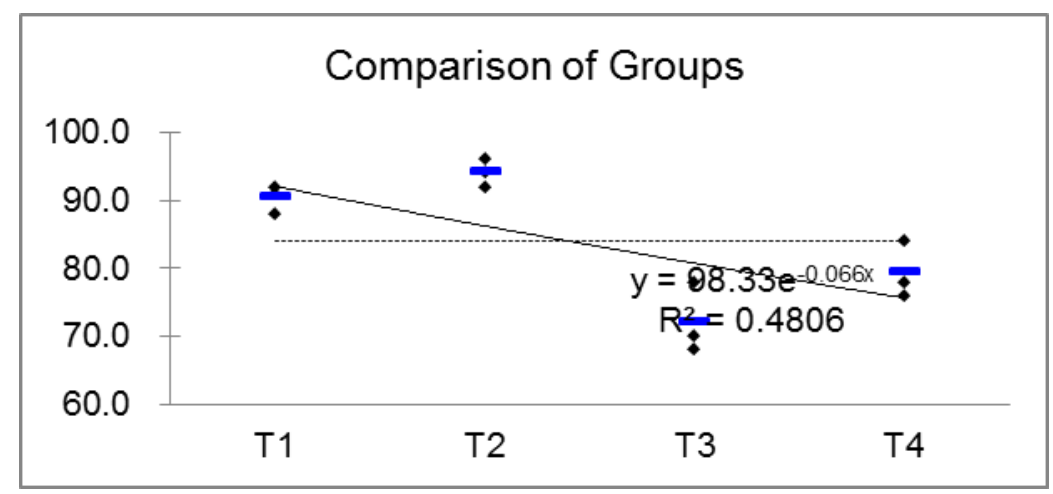

Figure 1: Comparison of the groups/treatments indicating that there is a highly significant interaction of the points to the different treatments means in terms of percent weight loss $(\%)$.

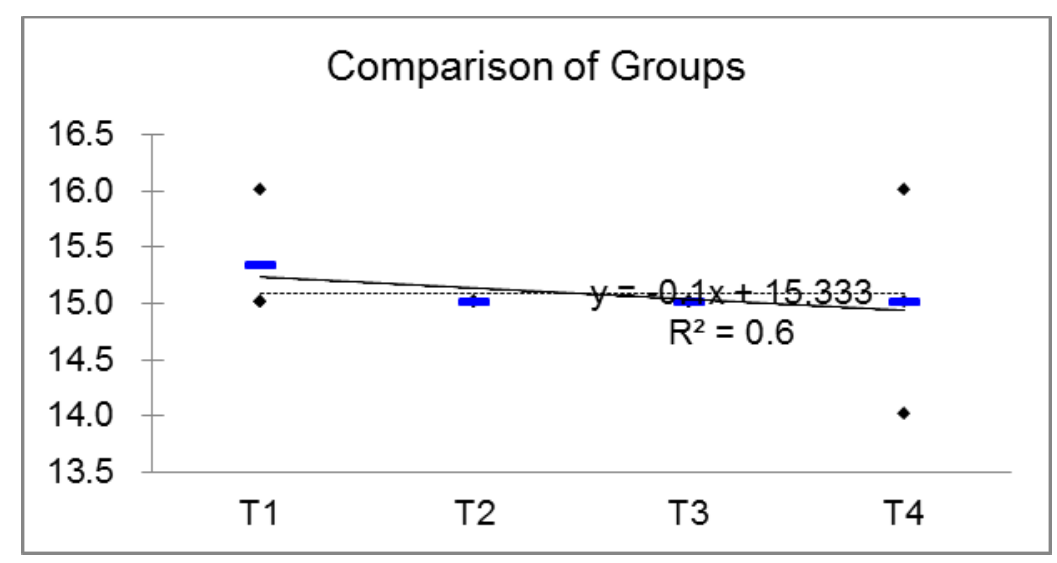

Figure 2: Comparison of the groups/treatments indicating that there is a significant interaction of the points to the different treatments means in terms of color change, color indices. 


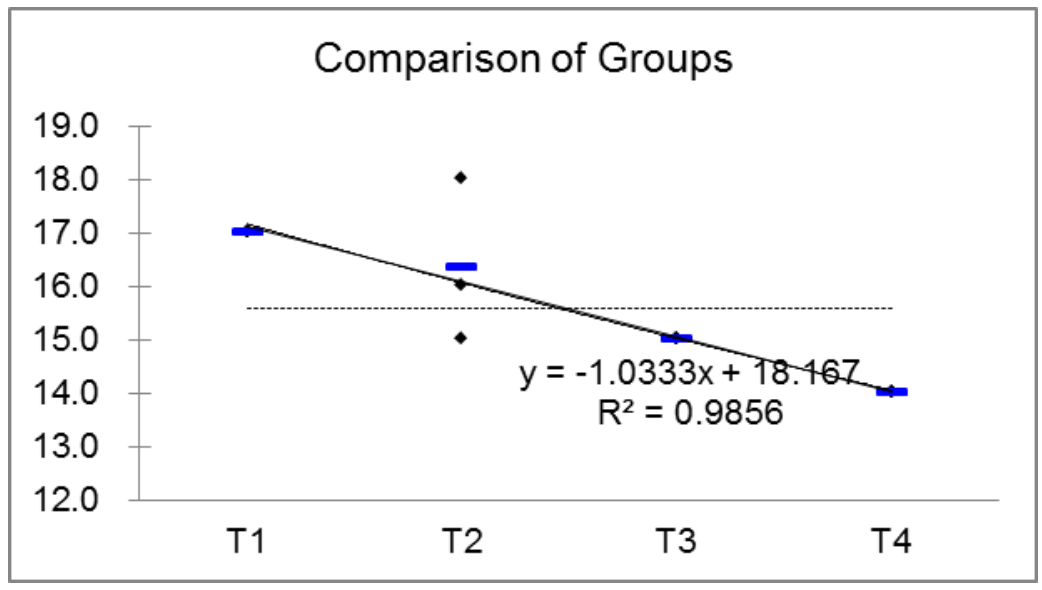

Figure 3: Comparison of the groups/treatments indicating that there is a highly significant interaction of the points to the different treatments means in terms of degrees of wilting $(\%)$.

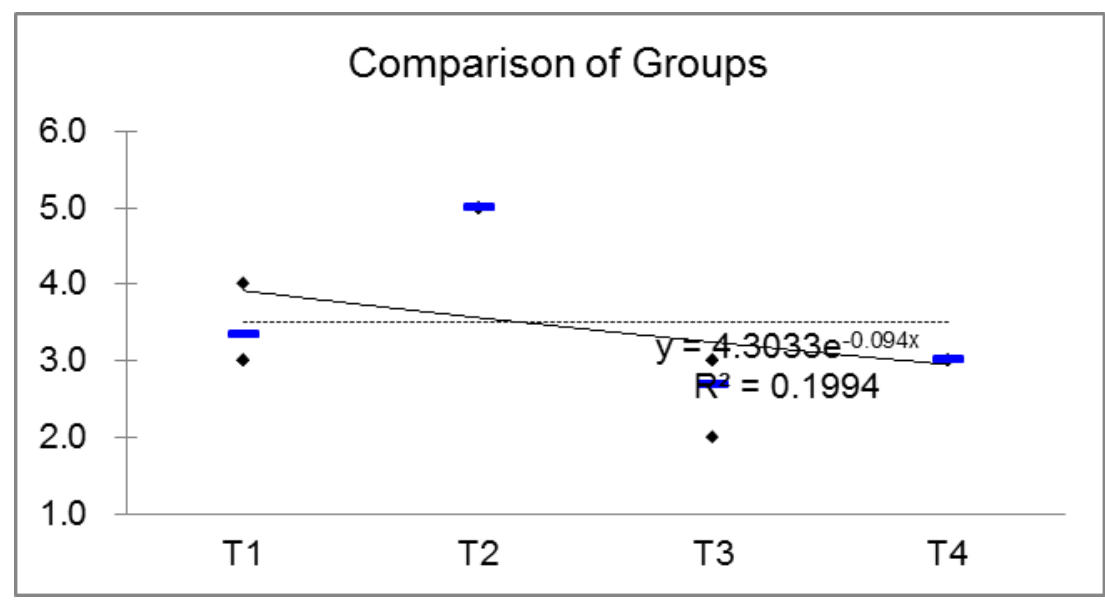

Figure 4: Comparison of the groups/treatments indicating that there is a highly significant interaction of the points to the different treatment means of the number of days the crop becomes unfit for consumption (early and last longer).

\section{CONCLUSIONS}

Generally fruits and vegetable quality deteriorated during storage as weight loss decreased and increased. Firmness decreased during the storage, regardless of the vegetable, and was the most important limiting quality factor for most vegetables evaluated. Therefore, first observed is the water loss was perceived as a loss of pechay and the turgidity, softening of the entire pechay leaf/leaves. Changes in color usually followed in tissue firmness. Vegetable developed a dark coloration and overripe (over storage) appearance, became green to $75 \%$ yellow, and less bright green. Shriveled, wilted dry appearance developed when only textural and color changes were already noticeable at the same time as weight loss attained a maximum threshold, which was dependent on the vegetable evaluated (pechay). However, a significant linear correlation was found between the other treatments and parameters like weight loss, several days the crops become unfit for consumption and degrees of wilting.

Therefore, maximum postharvest life, when the vegetable became unacceptable for sale to impaired visual quality under the different storage used in this study. Deterioration of vegetable, visual quality may not be exclusively attributed to water loss, but rather to a summation of many appearance defects, some of which may result from excessive loss of water. 
Further investigations should be carried out to identify the optimum quality of the crops that were used in this study and determine the threshold level that does not compromise the leafy vegetable quality.

\section{REFERENCES}

1. Adel A. Kader. 2000. Department of Plant Sciences, University of California, Davis. The Postharvest Technology University of California Davis.

2. Cantwell, M., and T. Suslow.2015. "Fruit Ripening \& Ethylene Management. Department of Plant Sciences, University of California, Davis. http://postharvest.ucdavis.edu/pfvegetable/

3. Damaso, A. V. 2020. Growth and Yield of High Protein Corn (Zea mays, L) as Influenced by Plant Spacing and NPK Levels. Faculty of College of Agriculture, Nueva Ecija University of Science and Technology - Gabaldon Campus, Gabaldon, Nueva Ecija 3131. Philippines. International Journal of Mechanical and Production Engineering Research and Development (IJMPERD) ISSN(P): 2249-6890; ISSN(E): 2249-8001 Vol. 10, Issue 3, Jun 2020, 2025-2032 @ TJPRC Pvt. Ltd.

4. Emond, J. P. 2007. Relationship Between Weight Loss and Visual Quality of Fruits and Vegetables. University of FloridaIFAS, Food Science and Human Nutrition Department Gainsville, FL 32611-0720

5. Kader, A.A. 2001. Quality assurance of harvested horticultural perishables. Acta Hort. 553:51-56

6. Mabberley, D.J. 1987. The Plant Book. A Portable Dictionary of the Higher Plants. Cambridge University Press, Cambridge. 706 pp. ISBN 0-521-34060-8

7. Nunes, C. N. 2007. Relationship Between Weight Loss and Visual Quality of Fruits and Vegetables. University of FloridaIFAS, Food Science and Human Nutrition Department Gainsville, FL 32611-0720

8. O'Hare et al., 2001. Effects of the methods of pre-treatment before freezing on the retention of chlorophylls in frozen leaf vegetables prepared for consumption. Eur Food Res Technol 226:25-31(2007).

9. Susanna Lyle. March 2006. Fruit \& nuts: a comprehensive guide to the cultivation, uses, and health benefits of over 300 foodproducing plants. Timber Press. Retrieved 11 June 2012.

10. Tamayo, N. V. 2013. Lecture Manual in Postharvest Handling and Seed Technology. Department of Crop Science, College of Agriculture. Central Luzon State University, Science City of Muñoz, Nueva Ecija.

11. Deshmukh, R., Babu, D. R., \& Rao, K. N. (2020). Pressure Testing Results (As A Decision Tool For Deciding Low Oxygen Or Ultra-Low Oxygen Or High Oxygen Storage) Of Semi-Hermetically Sealed Controlled Atmosphere Storage Insulated Chambers. IJMPERD, 10(1), 531-540.

12. Babu, D. R., Rao, K. N., Kumar, M. S., \& Kumar, B. S. (2018). Handling of apples during sorting-grading operation and measuring the mechanical properties firmness after controlled atmosphere storage. International Journal of Mechanical and Production Engineering Research and Development (IJMPERD) December.

13. Aipov, R. S., Gabitov, I. I., Valishin, D. E., Vokhmin, V. S., Linenko, A. V., Leontev, D. S., ... \& Kabashov, V. Y. (2019). Cylindrical linear induction motor with intermittent phase switching used in the borehole plunger pump drive with mechanical energy storage elements. Journal of Computational and Theoretical Nanoscience, 16(7), 2742-2749. 